\title{
Effects of virtual reality immersion and audiovisual distraction techniques for patients with pruritus
}

\author{
Vera Leibovici $\mathrm{MD}^{1}$, Florella Magora $\mathrm{MD}^{2}$, Sarale Cohen $\mathrm{PhD}^{2}$, Arieh Ingber $\mathrm{MD}^{1}$
}

V Leibovici, F Magora, S Cohen, A Ingber. Effects of virtual reality immersion and audiovisual distraction techniques for patients with pruritus. Pain Res Manage 2009;14(4):283-286.

BACKGROUND: Virtual reality immersion (VRI), an advanced computergenerated technique, decreased subjective reports of pain in experimental and procedural medical therapies. Furthermore, VRI significantly reduced pain-related brain activity as measured by functional magnetic resonance imaging. Resemblance between anatomical and neuroendocrine pathways of pain and pruritus may prove VRI to be a suitable adjunct for basic and clinical studies of the complex aspects of pruritus.

OBJECTIVES: To compare effects of VRI with audiovisual distraction (AVD) techniques for attenuation of pruritus in patients with atopic dermatitis and psoriasis vulgaris.

METHODS: Twenty-four patients suffering from chronic pruritus - 16 due to atopic dermatitis and eight due to psoriasis vulgaris - were randomly assigned to play an interactive computer game using a special visor or a computer screen. Pruritus intensity was self-rated before, during and $10 \mathrm{~min}$ after exposure using a visual analogue scale ranging from 0 to 10 . The interviewer rated observed scratching on a three-point scale during each distraction program.

RESULTS: Student's $t$ tests were significant for reduction of pruritus intensity before and during VRI and AVD $(\mathrm{P}=0.0002$ and $\mathrm{P}=0.01$, respectively) and were significant only between ratings before and after VRI $(\mathrm{P}=0.017)$. Scratching was mostly absent or mild during both programs. CONCLUSIONS: VRI and AVD techniques demonstrated the ability to diminish itching sensations temporarily. Further studies on the immediate and late effects of interactive computer distraction techniques to interrupt itching episodes will open potential paths for future pruritus research.

Key Words: Atopic dermatitis; Audiovisual distraction; Pruritus; Psoriasis; Virtual reality

\section{Effet des techniques d'immersion dans une réalité virtuelle et de distraction audiovisuelle chez des patients souffrant de prurit}

HISTORIQUE : L'immersion dans la réalité virtuelle (IRV), une technique informatique avancée, a exercé un effet à la baisse sur les symptômes douloureux signalés lors de traitements médicaux expérimentaux et interventionnels. De plus, l'IRV a significativement ralenti l'activité cérébrale liée à la douleur, mesurée au moyen d'épreuves d'imagerie par résonance magnétique fonctionnelle. La ressemblance entre les voies anatomiques et neuroendocriniennes de la douleur et du prurit pourrait contribuer à confirmer le rôle de l'IRV en traitement d'appoint lors des études de recherche fondamentale et clinique sur les aspects complexes du prurit.

OBJECTIFS : Comparer les effets de l'IRV et des techniques de distraction audiovisuelle (DAV) sur l'atténuation du prurit chez des patients souffrant de dermatite atopique et de psoriasis vulgaire.

MÉTHODES : Vingt-quatre patients atteints de prurit chronique, 16, souffrant de dermatite atopique et huit, de psoriasis vulgaire, ont été assignés aléatoirement soit à un jeu d'ordinateur interactif fonctionnant avec des lunettes spéciales, soit à un écran d'ordinateur. L'intensité du prurit a été autoévaluée avant, durant et dix minutes après l'exposition, à l'aide d'une échelle analogique visuelle graduée de 0 à 10 . L"intervieweur a classé les périodes de grattage observées sur une échelle en trois points durant chaque programme de distraction.

RÉSULTATS : Les tests $t$ de Student se sont révélés significatifs pour ce qui est de réduire l'intensité du prurit avant et durant l'IRV et la DAV ( $\mathrm{P}=$ 0,0002 et $\mathrm{P}=0,01$ respectivement) et n'ont été significatifs qu'entre les évaluations effectuées avant et après l'IRV $(P=0,017$. Les épisodes de grattage ont été pour ainsi dire inexistants, sinon légers, avec les deux programmes.

CONCLUSIONS : Les techniques d'IVR et de DAV se sont révélées capables d'atténuer temporairement les sensations prurigineuses. Des études plus approfondies sur les effets immédiats et retardés des techniques de distraction interactive par ordinateur utilisées pour interrompre les épisodes de démangeaisons paveront la voie aux futures recherches sur le prurit.

pathogenesis (3-5). In addition, recent findings have revealed the similar, although not identical, interactions that take place between the neural and endocrine systems that determine the transmission and central sensitization processes related to both itch and pain sensations $(6,7)$. Local measures and pharmacological means of therapy have not yet provided satisfactory results for the cure of pruritus and its link with the desire to scratch. The lack of specific therapy for pruritus as well as improved understanding of the complex neuroendocrine and psychological aspects, together with new data on the similar relationship between the structural systems controlling both pain and itch, have paved the way for the use of many nonpharmacological types of therapy for itching. The treatment strategies known to alleviate persistent pain include cognitive tion, but is the consequence of complex psychoneuroendocrin processes that determine the occurrence and maintenance of its 
behaviour therapy, biofeedback, hypnosis and various modalities of distraction (eg, music, imagery, etc) and have been added to the strategies of pruritis treatment $(8,9)$. These treatments were undertaken in an attempt to break the vicious itch/scratch cycle using their effect on the central control axis $(10,11)$.

With progress in technology, new methods of distraction have been introduced for the treatment of pain, namely virtual reality immersion (VRI) and the audiovisual distraction (AVD) method of therapy $(12,13)$. The VRI technique was described as an efficient nonconventional method for the relief of experimental ischemic $(14,15)$ and cold- and heat-producing pain (16) in human subjects. It has also been reported to be a promising new tool to reduce awareness of pain, unpleasantness and anxiety during procedural medical therapies $(13,17)$.

Virtual reality is a high-technology, interactive, computerbased distraction system that has the ability to occlude visual and auditory stimuli coming from the real environment and replace them with a videotaped interactive program of selected images and sounds transmitted via a specially designed visor. Hoffman et al (12) compared the alleviation of pain during burn dressing changes when using VRI therapy or a Nintendo computer game (Nintendo of America, Inc). Significantly better results were obtained with the virtual reality system (12). Subjective reports of pain alleviation were validated by functional magnetic resonance imaging evidence showing that VRI decreased pain-related brain activity (16).

The manner in which the use of virtual reality treatment influences and diminishes the pain experience is now under intensive research in several centres around the world. In view of the resemblance between the neuroendocrine pain and pruritus pathways, it is hypothesized that the virtual reality method will provide an adjunctive mode for disrupting severe itching episodes.

The purpose of the present study was to test the effects of VRI treatment on the self-reported intensity, quality and reactions to pruritus in patients suffering from atopic dermatitis and psoriasis vulgaris. Furthermore, the results obtained with the virtual reality equipment using a special visor in one group of patients will be compared with the results obtained in a second group of patients playing the same interactive game with an AVD system on a regular computer screen.

\section{METHODS}

\section{Participants}

The study population consisted of 27 consecutive patients with pruritus seen in the dermatology department and outpatient clinic of the Hadassah University Hospital (Jerusalem, Israel). Three patients were excluded from the study - two patients due to inability or lack of interest in using the computer, and one patient reported only a low level of current itching. Of the remaining 24 patients ( 12 women and 12 men, 18 to 84 years of age, mean age 44.5 years), six were hospitalized and 18 were outpatients; as well, 16 patients had atopic dermatitis and eight had psoriasis vulgaris. All suffered from an overall chronic pruritus (a score of more than 5 based on a visual analogue scale [VAS] of itching from 0 to 10). The study was approved by the University Human Studies Committee and informed consent was obtained from all participants following an explanation of the study. All study patients were on mild local corticosteroid treatment and/or emolients; no patients received systemic treatments such as antihistamines, cyclosporine, corticosteroids, methotrexate, retinoids or biological treatments. Severity of disease was evaluated according to the Psoriatic Area Severity Index for psoriasis, and the SCORing Atopic Dermatitis scale for atopic dermatitis. The psoriasis group included four patients with mild disease, two patients with moderate disease and two patients with severe disease. The atopic dermatitis group included five patients with mild disease, nine patients with moderate disease and two patients with severe disease. Nocturnal itching was particularly distressing in 13 patients.

\section{Experimental design}

The patients were randomly assigned to either a presentation program of VRI $(n=12)$ or AVD $(n=12)$. The same interactive game with accompanying music was played for each presentation mode. A brief medical history was taken before the presentation of each distraction program. Pruritus intensity was rated on a VAS of itching (0 to 10 ) immediately before the beginning of the program. Patients not familiar with computer games were given an opportunity to practice the game on the computer screen without music before starting the official session.

Itching was the major dependent variable. Patients rated intensity of itching three times on VAS scales immediately before the game and, retrospectively, immediately after the exposure (during) and $10 \mathrm{~min}$ after the game. Observed scratching was rated by the interviewer during each respective distraction program on a three-point scale: no scratching, a few light scratching movements or repeated scratching during the game.

\section{Equipment}

A regular Pentium laptop computer (Intel Corp, USA) with an NVIDIA graphics card (NVIDIA Corp, USA) was used. The AVD interactive game program was viewed on the computer screen with music provided through the computer speakers. For the VRI session, an eMagin Z800 3DVisor (eMagin Corp, USA) with stereo earbuds (www.emagin.com) connected with the laptop computer withdrew the patient from the real world using visual and audio sensory obstruction and replaced it with the output field of the same video-transmitted game used during the AVD session. The software used in the present study was a simple interactive commercial game that consisted of images of rapidly moving, colourful balls that needed to be caught in a net. The game was accompanied by lively music. After all the balls were caught, the screen lit up. The time it took to accomplish the task was shown and the game was automatically reset to be played again for a total of 10 trials. It took between $8 \mathrm{~min}$ and $12 \mathrm{~min}$ to complete the 10 trials.

\section{Statistical analyses}

Two-sided Student's $t$ tests were used for independent groups as well as for paired groups for within-group changes. The Bonferroni correction was applied and a level of $\mathrm{P}<0.025$ was used to establish significance.

\section{RESULTS}

Differences in background variables between the two distraction groups were tested using Student's $t$ tests for independent groups. Statistical evaluation of type of dermatological disease 
(atopic dermatitis or psoriasis vulgaris), severity of the disease, age, sex and computer experience indicated that the VRI and AVD groups were not statistically different $(\mathrm{P}>0.10)$ with respect to any of the background variables. Furthermore, the statistical evaluations of these background variables indicated that these variables were not significantly related to the intensity of itching during the distraction programs. Therefore, these background variables were not included in further analysis.

The mean itching intensity of the VRI group $(n=12)$ and of the AVD group $(n=12)$ was not significantly different at the beginning of the program (mean VAS scores 5.58 for the VRI group and 5.46 for the AVD group) (Table 1). The pruritus intensity scores during and after the trials were also not significantly different beween the VRI and the AVD groups $(\mathrm{P}>0.10)$.

Within-group change was tested using paired Student's $t$ tests for each presentation mode, comparing before-during and before-after itching intensity. Table 1 presents means and SDs of itching intensity scores before, during and 10 min after each presentation mode, as well as the level of significance. Tests for within-patient change for each technique indicated VRI yielded a significant reduction in itching intensity between the reported scores before and during game exposure $(\mathrm{P}=0.0002)$ and from before game exposure to $10 \mathrm{~min}$ after game exposure $(\mathrm{P}=0.01)$. AVD showed a significant reduction in itching scores reported before and during game exposure $(\mathrm{P}=0.017)$ whereas the reduction in reported scores reported before and after game exposure was minimal and not significant $(\mathrm{P}>0.10)$.

Many patients in each group reported a VAS score of 0 for itching intensity during the time they played the game $(50 \%$ for the VRI group and $42 \%$ for the AVD group). The effect began simultaneously with the commencement of the game. Itching VAS scores decreased markedly during exposure (greater than $50 \%$ reduction) in all patients except one in the VRI group and two in the AVD group who reported no change in VAS scores. These results indicate that participation in the game was effective for the two techniques. Scratch movements recorded by the experimenter indicated no scratching in 11 of the 12 patients during VRI and repeated scratching in one patient, whereas in the AVD group, no scratching occurred for five patients, some light scratching occurred in six patients and one patient continued to scratch repeatedly. Thus, objective observation suggested a somewhat better outcome in the intensity of itching resulting from playing the game with VRI than with the AVD. No deleterious effects of VRI were noted other than one patient in the VRI group who reported slight nausea.

\section{DISCUSSION}

Both methods of distraction, VRI and AVD, captured the attention of patients as they focused their concentration on playing the interactive computer game, which resulted in a significant reduction of reported intensity of itch and a reduced amount of observed scratching. It is noteworthy that the effect was concomitant with the beginning of the game in all of the patients examined from both groups who experienced a VAS score of 0 or a decrease in itching intensity during the game. Because these two interactive computer methods produce a prompt transition of the pruritus and itch sensations to a period
TABLE 1

Pruritus intensity ratings before, during and $10 \mathrm{~min}$ after exposure to virtual reality immersion (VRI) and audiovisual distraction (AVD)

\begin{tabular}{lcclllll}
\hline & \multicolumn{3}{c}{ VRI $(\mathbf{n}=12)$} & & \multicolumn{3}{c}{ AVD $(\mathbf{n}=12)$} \\
\cline { 2 - 4 } \cline { 6 - 8 } & Before & During & After & & Before & During & After \\
\hline Mean & 5.58 & $1.23^{* *}$ & $3.25^{* * *}$ & & 5.46 & $2.75^{*}$ & 4.75 \\
SD & 1.99 & 1.62 & 2.08 & & 2.31 & 3.02 & 2.74 \\
\hline
\end{tabular}

'During' intensity ratings were reported immediately after exposure to VRI or AVD. ${ }^{*} P=0.017 ;{ }^{* *} P=0.0002$ before versus during; ${ }^{* *} P=0.0$ before versus after

free from these unpleasant feelings, they may potentially contribute additional techniques to the analysis of the basic processes related to pruritis.

Pruritic stimuli are under the influence of complex neurobiological inhibitory and stimulatory processes that continuously modulate their afferent and efferent transmission to and from the central nervous system $(5,17)$. Investigations using functional positron emission tomography and functional magnetic resonance imaging in healthy volunteers exposed to heat pain stimulation or itch caused by histamines revealed the presence of increased activity in multiple regions located in the spinal cord and the brain (18-20). Stimulation of these specific areas of the central nervous system generates the perception of itching, leading to scratching $(21,22)$. Our study confirms the hypothesis that diverting attention may account for the decrease of both itch sensations and scratching movements, similar to the effect of distraction reported in pain conditions (23). However, as with pain, the brain is also the originator of powerful descending inhibitory influences that counterbalance the pruritus stimulatory course of events (5). VRI and AVD computer game techniques introduce a powerful distraction element via the brain that sets in motion the pruritus inhibitory mechanisms. Distraction experiments in mice were videotaped for counting serotonin (5-hydroxytryptamine)-induced scratching movements. The reduced number of scratching movements observed on the video suggested that scratching was greatly influenced by distraction (24).

The results obtained suggest that VRI may have been somewhat more effective than AVD because it augments detachment from viewing and hearing what is happening in the environment. However, it is important to point out that the AVD method is easier to use, cheaper to obtain, available in the homes of large populations in many countries and is thus familiar to many patients suffering from pruritus. Pruritus is most severe during evenings and nights, when patients are free to concentrate more on their symptoms. Some patients who complain of nocturnal itching make use of extremely harmful measures such as very hot showers and application of lemon juice on wounds to get relief. The availability of the AVD method is an advantage compared with VRI because it may serve to shorten pruritus episodes occurring at night.

It is known that itching sensations that advance into chronic pruritus, similar to the nociceptive type of syndromes, may lead to a phase of central sensitization characterized by higher perceived itching sensation in the presence of minimal or even absent pruritic stimulation. To take advantage of the complex inhibitory physiology of itching and avoid the development of sensitization, multimodal general measures for 
treatment and numerous drug options and psychosomatic methods have been advocated $(17,25)$. Furthermore, additional modalities and numerous types of conventional distractors, such as music and imagery, have been tested and await confirmation by rigorous trials (8-10).

The same applies to the results of the present report, albeit with a small number of patients, which reveal a transient beneficial effect of the two distraction methods for alleviation of itching.

For these two methods to join the nonpharmacological list of pruritus therapeutic options, future research is needed to closely examine the effects of exposure to the VRI and AVD methods during extended periods of time and with even more engaging distractions. It is also essential to seek software programs appropriate for differences in age, sex and cultural background.

The known psychoneuroendocrine aspects of pruritus, together with the recommended multimodalities for its treatment, call for a closer interdepartmental collaboration for the study and treatment of pruritus. Moreover, the recognized marked relationship between the central and peripheral pathways of itch and pain indicate the important contribution multidisciplinary pain clinics make to the application of complex treatment programs and the development of new modalities for the relief of chronic pruritus.

\section{REFERENCES}

1. Wahlgren CF. Itch and atopic dermatitis: An overview. J Dermatol 1999;26:770-9.

2. Yosipovitch G, Goon A, Wee J, Chan YH, Goh CL. The prevalence and clinical characteristics pruritus among patients with extensive psoriasis. Brit J Dermatol 2000;143:969-73.

3. O'Sullivan RL, Lipper G, Lerner EA. The neuro-immunocutaneous-endocrine network: Relationship of mind and skin. Arch Dermatol 1998;134:1431-35.

4. Roosterman D, Goerge T, Schneider W, Bunnet NW, Steinhoff M. Neuronal control of skin function: The skin as a neuroimmunoendocrine organ. Physiol Rev 2005;86:1309-73.

5. Paus R, Schmetz M, Biro T, Steinhof M. Frontiers in pruritus research: Scratching the brain for more effective itch therapy. J Clin Invest 2006;116:1172-85.

6. Schmelz M. Complex interaction between pain and itch. Pain 2006;24:9-10.

7. Stander S, Schmetz M. Chronic itch and pain - similarities and differences. Eur J Pain 2006;10:473-78.

8. Shenenfelt PD. Biofeedback, cognitive-behavioral methods, and hypnosis in dermatology: Is it all in your mind? Dermatol Ther 2003;16:114-22.

9. Lazaroff I, Shimshoni R. Effects of medical resonance therapy music on patients with psoriasis and neurodermatitis - a pilot study. Integr Physiol Behav 2000;35:189-98

10. Sarti MG. Biofeedback in dermatology. Clin Dermatol 1998;16:711-14.

11. Twycross R, Greaves MW, Handwerker H, et al. Itch: Scratching more than surface. J Med 2003;96:7-26

12. Hoffman HG, Doctor JN, Patterson DR, Carrougher GJ, Furness TA III. Virtual reality as an adjunctive pain control during burn care in adolescent patients. Pain 2000;85:305-9.

13. Patel A, Schieble T, Davidson M, et al. Distraction with a handheld video game reduces pediatric preoperative anxiety. Paediatr Anaesth 2006;16:1019-27.

14. Hoffman HG, Garcia-Palacios A, Beecher VKJ, Sharar SR. Immersion virtual reality for reducing experimental ischemic pain. J Hum Comput Inter 2003;15:469-86.

15. Magora F, Cohen S, Shochina M, Dayan E. Virtual Reality Immersion Method of distraction to control experimental ischemic pain. Isr Med Assoc J 2006;8:261-65.

16. Hoffman HG, Richards TL, Coda B, et al. Modulation of thermal pain-related brain activity with virtual reality: Evidence from fMRI. Neuroreport 2004;15:1245-8.

17. Biró T, Ko MC, Bromm B, et al. How best to fight that nasty itch from new insights into the neuroimmunological, neuroendocrine, and neurophysiological bases of pruritus to novel therapeutic approaches. Exp Dermatol 2005;14:225-40.

18. Mochizuki H, Tashiro M, Kano M, Sakurada Y, Itoh M, Yanai K. Imaging of central itch modulation in the human brain using positron emission tomography. Pain 2003;105: 339-46.

19. Drzega A, Darsow U, Treede RD. Central activation by histamineinduced itch: Analogies to pain processing; a correlational analysis of o-15 positron emission tomography studies. Pain 2001;92:295-305.

20. Leknes SG, Bantick S, Willis CM, Wilkinson JD, Wise RG. Itch and motivation to scratch: An investigation of the central and peripheral correlates of allergen and histamine induced itch in humans. J Neurophysiol 2007;97:415-22.

21. Steinhoff M, Bienenstock J, Schmetz M, Maurer M, Wei E, Biro T. Neurophysiological, neuroimmunological, and neuroendocrine basis of pruritus. J Invest Dermatol 2006;126:1705-18.

22. Ikoma A, Rukwied R, Ständer S, Steinhoff M, Miyachi Y, Schmelz M. Neurophysiology of pruritus: Interaction of itch and pain. Arch Dermatol 2003;139:1475-8.

23. Wismeijer AA, Vingerhoets AJ. The use of virtual reality and audiovisual eyeglass systems as adjunct analgesic techniques: A review of the literature. Ann Behav Med 2005;30:268-78.

24. Yamaguchi T, Nagasawa T, Satoh M, Kuraishi Y. Itch-associated response induced by intradermal serotonin through 5 -HT2 receptors in mice. Neurosc Res 1999;35:77-83.

25. Graves MV. Recent advances in pathophysiology and current management of itch. Ann Acad Med Singapore 2007;36:788-92. 


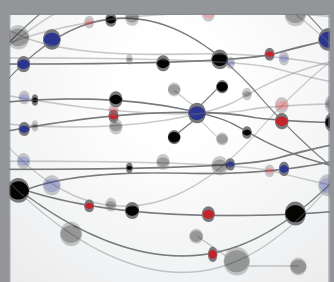

The Scientific World Journal
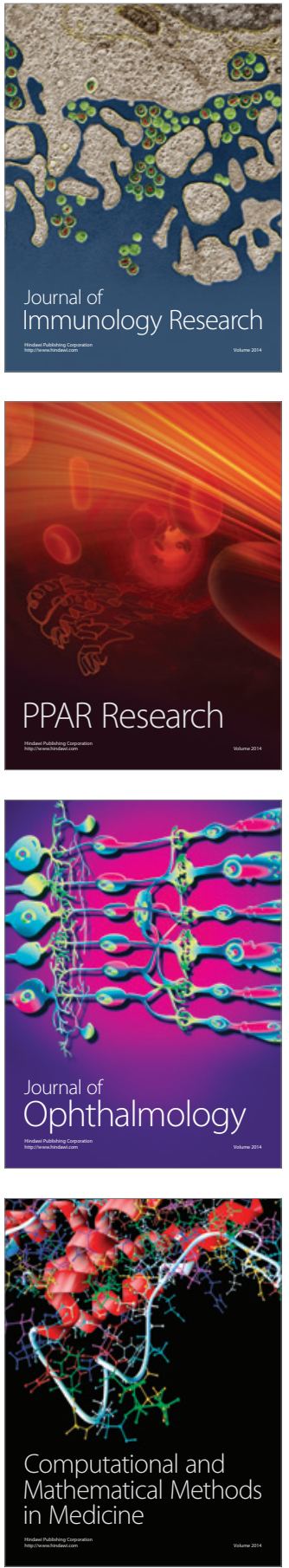



Gastroenterology Research and Practice

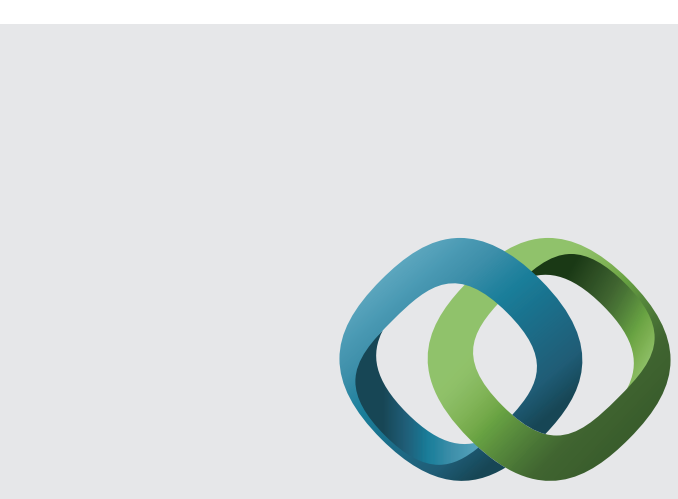

\section{Hindawi}

Submit your manuscripts at

http://www.hindawi.com
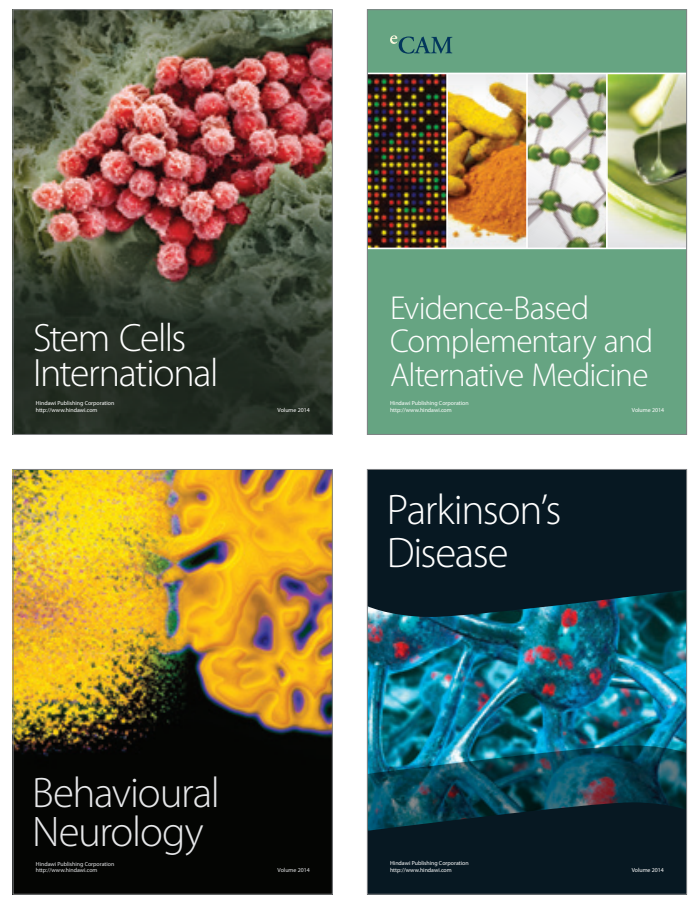
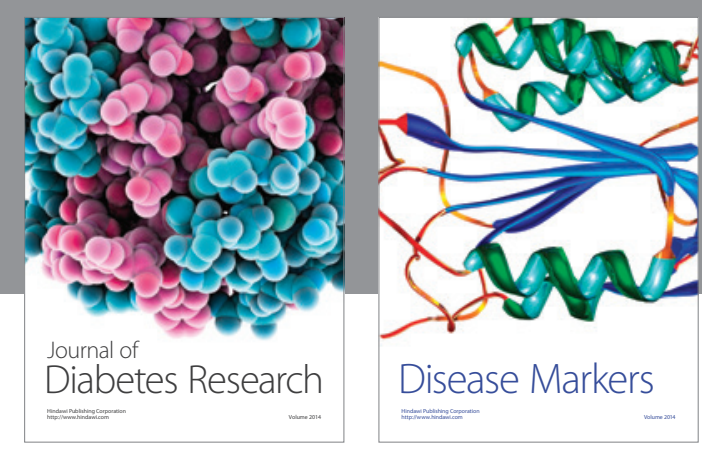

Disease Markers
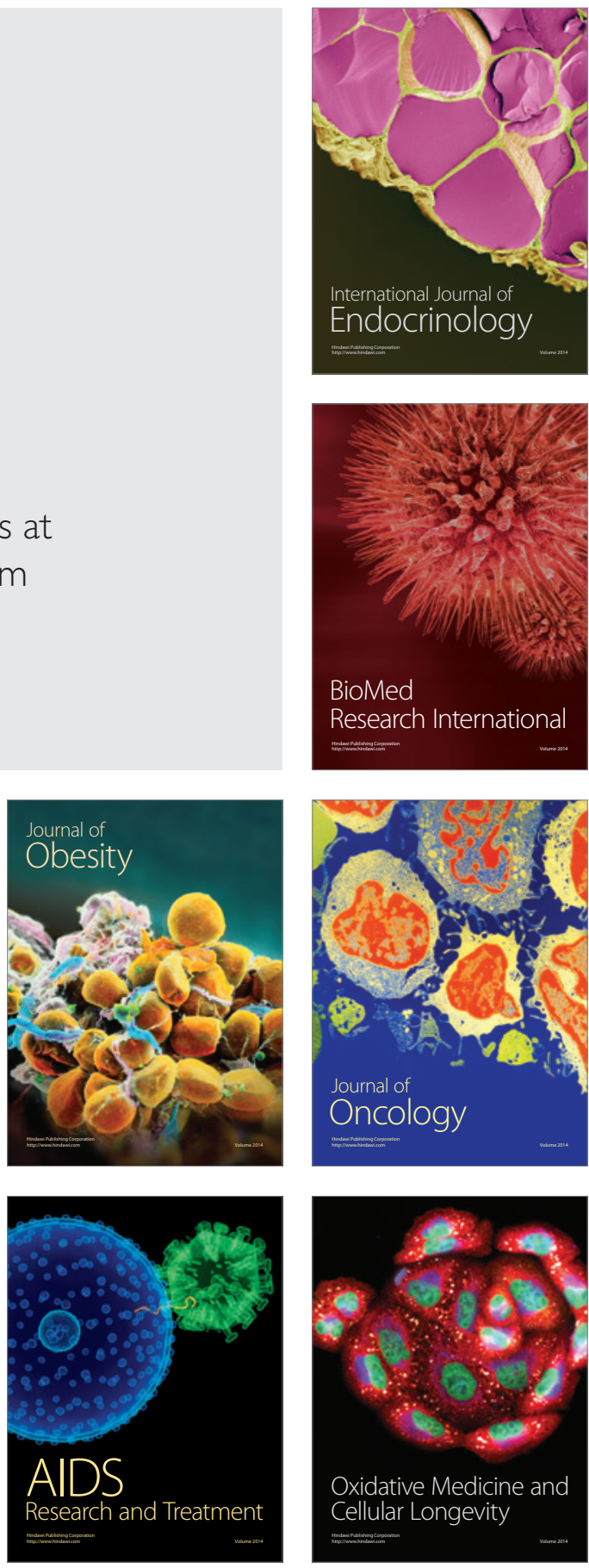